\title{
ARTICLES
}

\section{DEVASTATING REPERCUSSIONS OF COVID-19 PANDEMIC ON IMPOVERISHED CHILDREN}

Ms. Chitra Sharma*

*Ph. D Scholar, Himalayan University, Arunachal Pradesh, India. DOI: http://doi.org/10.47211/idcij.2020.v07iws01.002

Received $30^{\text {th }}$ June 2020, Accepted $25^{\text {th }}$ July 2020, Available online $30^{\text {th }}$ July 2020.

\section{ABSTRACT}

Devastating repercussions of COVID-19 on children, especially impoverished children can be detected. It has been sensed that this disaster affects every domain of the lives of human beings. It is traumatic. And trauma always plummets hardest on the little ones. Children, especially poor children fetch the incredible burden during the COVID-19 pandemic. Innocent children are severely affected by this coronavirus. This pandemic drastically affects multiple areas including health, educational impacts, economic bangs, safety and protection issues, influences on civic space and participation, etc.

Key Words: COVID-19 pandemic, especially impoverished children.

\section{ABOUT AUTHORS}

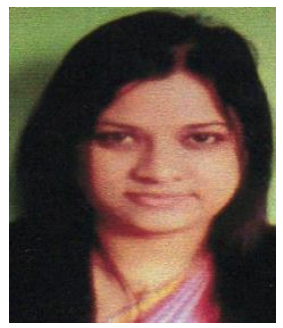

Author Ms. Chitra Sharma is a Ph. D. Scholar in Himalayan University, Arunachal Pradesh, India. 


\section{INTRODUCTION}

Drastic repercussions are seen on COVID-19 related disruption to vaccination, nutrition and other vital health services. According to an analysis, vaccine interruptions triggered by the COVID-19 pandemic are anticipated to have a profound repercussion on the immunization facilities in the developing countries. Immunization in the most faraway parts of India is being accomplished by the Accredited Social Health Activist (ASHA) or Community Health Workers who work under the Ministry of Health and Family Welfare. In response to the COVID-19 outbreak, ASHA has been charged with various duties pivoted around the pandemic control like piloting door to door surveys, managing consciousness campaigns among people, supervising the movement of migrants, sensitisation for social distancing, etc. Consequently, ASHA workers are not able to provide immunization services to children, pregnant women or birth control methods on account of their enlarged control measures. Even scarcity of vaccines which were scheduled to give during pregnancy has been experienced.

The children have been aside from schools for a number of months because of this pandemic. Families in poverty already noticed it much harder to supply their children with a rich home learning environment. Awful stress, worries about money, overcrowded housing and insufficient resources make day to day life more difficult. It is nearly on impossible for academic learning to take place when a child's basic needs like shelter, adequate nutrition and affability cannot first be met. The economic trauma of coronavirus means many more families will find themselves wondering how they can pay the rent, hit their homes and put food on the table. This will seriously impede parents' ability to support their little ones with home learning. Many children from low income families depend on free school mid-day meals for their daily nutrition, for example, low income parents cannot always provide childcare when their school age kids are instantaneously home all day. As schools across the nation hang virtual learning in alternative traditional classroom instruction, the millions of families that lack ingress to high speed internet might be out of luck.

People living in scant and overcrowded housing may experience intensified strain and conflict which generally affect the mental and physical health of the children. Some indigenous, refugees, as well as low income families living with financial stress along with insecurity of food are exceptionally vulnerable. Forced segregation and financial uncertainty may lead to grow in family violence, endowing to mental and physical trauma of the children. Lack of social and structured routines may lead to increase screen time, decrease physical activity, lack of concentration along with expansion of anxiety and early depression.

The international economic deterioration caused by COVID -19 pandemic, including enormous global job losses is probably to expand rates of child labour and child marriage. Millions of impoverished children were engaged in child labour before COVID-19 pandemic. And many of them were engaged in hazardous work. It is obvious that child labour is highly connected with economic shocks experienced by a family, like illness, disability or a parent's dropping of employment.

\section{CONCLUSIONS:}

Millions of children are detained in the justice system of cramped in orphanages and further organizations. In numerous such conveniences, children are clench in near proximity to other children with finite outpouring of water and sanitation which may faster the spread of infectious diseases like COVID-19. Access to basic medical services is also frequently deficient or dearth of these settings putting children's health at prominent risk if they fall sick. Similarly, millions of refugees, migrants and internally displaced children live in overcrowded camps, informal reception centres or smaller settlements where basic COVID -19 preventions measures like frequent hand washing, sanitizing and social distancing are nearly impossible. It is visible that the vast movement of immigrant workers and their families with children are heading back to their homes in rural areas. The journey for these children was painful and devastating enough. And many of them continued to suffer from abuse, uncertainty, stigma and discrimination even after they reached homes.

In any emergency circumstance be it war, natural calamities or pandemics children especially those who belong to socio-economically backward or poverty- stricken and marginalised communities, end up becoming the most vulnerable demographic. So they need special attention from their respective parents, neighbours, society and Government also. 